\title{
Polpa de Banana, Água de Coco e Carvão Ativado no Desenvolvimento in vitro de Lycaste sp.
}

\section{Banana Pulp, Coconut Water and Activated Carbon in in vitro Development of Lycaste sp.}

\author{
Wesley Machado*a; André Sarabia Zamarian ${ }^{\mathrm{a}}$
}

a UNOPAR. PR, Brasil.

*E-mail: w.machado@agronomo.eng.br

\begin{abstract}
Resumo
O objetivo deste trabalho foi avaliar o desenvolvimento inicial in vitro de plântulas da espécie de orquídea Lycaste sp. em meio de cultura com a adição de polpa de banana, água de coco e carvão ativado. O experimento foi conduzido em laboratório na Unopar, em Londrina, Paraná. Foi utilizado o meio de cultura MS (Murashige e Skoog) como suporte para o desenvolvimento das plântulas. As plântulas germinadas in vitro foram transferidas para meios de cultura, contendo as seguintes combinações: sem adição e com a combinação de polpa de banana e água de coco em meio (MS) com a concentração de totais de sais e meio com metade dos sais, acrescidos com e sem carvão ativado. Observou-se que os meios com concentração total de sais, água de coco e sem carvão ativado obtiveram um melhor resultado em comparação com o restante dos meios. As plântulas da espécie estudada não se desenvolveram em meio de cultura acrescido com polpa de banana, em função de oxidação. Baseado nos resultados, é possível concluir que a utilização de complexos nutritivos orgânicos afeta diretamente no desenvolvimento das plantas de Lycaste $s p$.
\end{abstract}

Palavras-chave: Orquídea. Complexos Nutritivos. Cultivo in vitro.

\begin{abstract}
The objective of this work was to evaluate the initial in vitro development of the orchid species Lycaste sp. in culture medium with the addition of banana pulp, coconut water and activated charcoal. The experiment was carried out in a laboratory at Unopar, in Londrina, Paraná. MS (Murashige and Skoog) culture medium was used as support for seedling development. In vitro germinated seedlings were transferred to culture media containing the following combinations: without addition and with the combination of banana pulp and coconut water in (MS) medium with total salt concentration and half with half salts, added with and without activated charcoal. It was observed that the media with total salt concentration, coconut water and without activated carbon obtained a better result compared to the rest of the media. There was no development of seedlings of the studied species with the use of banana pulp due to the oxidation. Based on the results, it can be concluded that the use of organic nutrient complexes directly affects the development of Lycaste sp.
\end{abstract}

Keywords: Orchids. Nutritional Complexes. In Vitro Cultivation.

\section{Introdução}

As orquídeas, pertencentes à família Orchidaceae, são plantas que por muito tempo são cultivadas pelo homem, e vêm com o passar dos anos sendo extintas de seu habitat natural. Isso se deve a sua difícil forma de propagação natural por semente que depende de uma simbiose com fungos, como, por exemplo, as micorrizas (TEIXEIRA et al., 2016)

No entanto, em condições de laboratório, é possível fazer a propagação por sementes por um processo assimbiótico, por meio de técnicas de micropropagação, possibilitando multiplicar milhares de plantas de orquídeas. $\mathrm{Na}$ micropropagação, é possível multiplicar esta espécie, visto que praticamente todas as sementes germinam sem a necessidade da simbiose. Além disso, estas técnicas produzem mudas de boa sanidade, em um menor tempo de produção e com melhor qualidade (SOUZA et al., 2016).

Para que ocorra um bom desenvolvimento destas plantas in vitro, há necessidade de controlar os fatores, como assepsia, ambiente (temperatura e luminosidade) e o meio de cultura
(MENEGHETTI et al., 2019). O meio de cultura é o fator mais importante, no desenvolvimento in vitro, pois é nesse que a planta irá buscar os nutrientes para a sobrevivência. No meio nutritivo é feita a adição de sais como macro e micronutrientes, que são essenciais para o crescimento da planta, também é acrescido carboidrato como fonte de carbono, além de água, vitaminas, hesitol e reguladores de crescimento, para que haja um crescimento satisfatório. O balanço entre esses elementos é fundamental (KURITA; TAMAKI. 2014).

Os reguladores de crescimento são determinantes para o crescimento das plântulas e para que haja um padrão de desenvolvimento (LONGO et al., 2016). Entre esses estão as auxinas e as citocininas. As citocininas atuam como promotoras de divisão celular, que promovem uma quantidade expressiva de produção de brotos, já as auxinas estão envolvidas no alongamento celular, contribuindo para desenvolvimento das plantas (BARRUETO CID, 2005).

Além de reguladores de crescimento, misturas complexas como: água de coco, polpa de banana e carvão ativado são 
usadas como aditivos em vários meios nutritivos (CALDAS et al., 1998). Estes aditivos possuem seus próprios sais minerais e, também, citocininas e auxinas, como é o caso da água de coco e da polpa de banana. O carvão ativado é um estimulador de enraizamento e diminuidor da intoxicação da planta por compostos fenólicos (TISSERAT, 1982; ZENG, S. et al. 2016).

O objetivo deste trabalho foi comparar o efeito da água de coco, polpa de banana, carvão ativado com o meio de cultivo MS (MURASHIGE; SKOOG, 1962) no crescimento da espécie Lycaste sp. in vitro.

\section{Material e Métodos}

O experimento foi conduzido no laboratório de biotecnologia da Universidade Norte do Paraná, LondrinaPR. Foi utilizada a espécie Lycaste sp. L.

Foi coletada uma cápsula de orquídea amadurecida. Esta cápsula foi levada para o laboratório e, em câmara de fluxo laminar, foi desinfestada em álcool $70 \%$ por um minuto e lavada três vezes com água destilada autoclavada. Em seguida, foi realizada lavagem por 15 minutos com hipoclorito de sódio a 2,5\% sob agitação constante. Para retirada do resíduo de hipoclorito, a cápsula foi lavada três vezes com água destilada esterilizada. Após a desinfestação superficial, a cápsula foi aberta com auxílio de um bisturi e as sementes retiradas.

As sementes foram espalhadas em meio de cultivo MS (MURASHIGE; SKOOG, 1962), preparado com a metade da concentração dos sais e com a adição de $1,5 \mathrm{~g} \mathrm{l}^{-1}$ de carvão ativado. As sementes foram submetidas ao escuro durante 15 dias.

Após 45 dias de germinação, as plântulas foram submetidas a 16 tratamentos diferentes no esquema fatorial de $2 \times 2 \times 2$, conforme apresentado nos Quadros 1 e 2. Os tratamentos são o resultado da combinação do uso de dois meios de cultivo, o meio MS, conforme descrito pela literatura, e o meio MS, usando a metade dos sais e com três combinações diferentes do uso de polpa de banana e água de coco, com adição ou não adição de carvão ativado aos meios de cultivo.

Quadro 1 - Tratamentos referentes ao meio de cultivo MS normal

\begin{tabular}{|c|c|c|c|c|}
\hline Tratamentos & $\begin{array}{c}\mathbf{1 5 0} \mathbf{~ m g ~ l}^{-1} \text { polpa de } \\
\text { banana }\end{array}$ & $\mathbf{1 5 0} \mathbf{~ m l ~ l} \mathbf{- 1}^{\text {água de coco }}$ & $\begin{array}{c}\text { Água de coco e polpa de } \\
\text { banana }\end{array}$ & Controle \\
\hline Sem carvão & A & B & C & D \\
\hline Com carvão & A11 & B11 & C11 & D11 \\
\hline
\end{tabular}

Letras e números destacam o tipo de tratamento e a combinação dos tratamentos.

Fonte: Dados da pesquisa.

Quadro 2 - Tratamentos referentes ao meio de cultivo MS metade dos sais

\begin{tabular}{|c|c|c|c|c|}
\hline Tratamentos & $\begin{array}{c}\mathbf{1 5 0} \mathbf{~ m g ~ l}^{\mathbf{1}} \text { polpa de } \\
\text { banana }\end{array}$ & $\mathbf{1 5 0} \mathbf{~ m l ~ l} \mathbf{- 1}^{\mathbf{a} g u a}$ de coco & $\begin{array}{c}\text { Água de coco e polpa de } \\
\text { banana }\end{array}$ & Controle \\
\hline Sem carvão & A2 & B2 & C2 & D2 \\
\hline Com carvão & A22 & B22 & C22 & D22 \\
\hline
\end{tabular}

Letras e números destacam o tipo de tratamento e a combinação dos tratamentos.

Fonte: Dados da pesquisa.

$\mathrm{O} \mathrm{pH}$ de todos os meios de cultura foram ajustados para $5,8 \pm 0,01$ e esterilizados em autoclave, em temperatura de $121^{\circ} \mathrm{C}, 1 \mathrm{kgf} \mathrm{cm}{ }^{-2}$ durante 21 minutos e, depois resfriados. Cada parcela experimental foi composta de 50 explantes cada. $\mathrm{O}$ delineamento experimental foi em blocos casualizados. As placas foram incubadas em sala de crescimento a uma temperatura de $26 \pm 2{ }^{\circ} \mathrm{C}$ e fotoperíodo de 16 horas.

Foram avaliados a quantidade de número de brotos e a porcentagem de oxidação dos explantes. Para a quantidade de número de brotos foram contabilizados aqueles que estavam emitindo os primeiros primórdios foliares. Para a porcentagem de oxidação se avaliaram aqueles que estavam em processo de senescência com a coloração marrom visível. Os dados obtidos foram submetidos a análise de variância e comparados pelo método de Scott-Knott a 5\% de probabilidade.

\section{Resultados e Discussão}

O Quadro 3 mostra a média do número de brotos de acordo com os tratamentos. Os resultados demonstraram que o uso de diferentes formulações de meios de cultivo influenciou no desenvolvimento das plântulas. O meio de cultivo MS normal com adição de água de coco e carvão ativado apresentou o melhor resultado $(7,70)$. Os resultados mostraram que o meio MS normal e aquele suplementado com carvão não apresentaram diferença significativa no número de brotos. Por outro lado, a adição de carvão ativado e água de coco causou aumento no número de brotações no meio MS metade dos sais.

A utilização do meio de cultivo MS, conforme descrito pela literatura, sem suplementação obteve um maior número de brotos $(4,20)$ em comparação com a utilização do meio MS, usando a metade dos sais sem suplementação $(1,90)$. Contudo, foi observado que a suplementação com a adição do carvão ativado, a adição de água de coco ou a adição de ambos, aumentou significativamente a média de formação de brotos no meio MS com a metade dos sais, apresentando uma média de 5,10, 4,50 e 4,40, respectivamente (Quadro 3). 
Quadro 3 - Média do número de brotos em relação aos tratamentos testados

\begin{tabular}{|c|c|c|}
\hline Abreviação & Tratamento & Média* \\
\hline $\mathrm{A}$ & MS e polpa de banana & $1,20 \mathrm{c}$ \\
\hline $\mathrm{B}$ & MS e água de coco & $3,00 \mathrm{c}$ \\
\hline $\mathrm{C}$ & MS, polpa de banana e água de coco & $0,80 \mathrm{c}$ \\
\hline $\mathrm{D}$ & MS & $4,20 \mathrm{~b}$ \\
\hline A11 & MS, carvão e polpa de banana & $2,10 \mathrm{c}$ \\
\hline $\mathrm{B} 11$ & MS, carvão e água de coco & $7,70 \mathrm{a}$ \\
\hline $\mathrm{C} 11$ & MS, carvão, p. banana e água de coco & $1,10 \mathrm{c}$ \\
\hline D11 & MS e carvão & $4,60 \mathrm{~b}$ \\
\hline $\mathrm{A} 2$ & MS1/2 e polpa de banana & $1,30 \mathrm{c}$ \\
\hline B2 & $\mathrm{MS}^{1} / 2$ e água de coco & $4,50 \mathrm{~b}$ \\
\hline $\mathrm{C} 2$ & MS $1 / 2$, polpa banana e água de coco & $0,50 \mathrm{c}$ \\
\hline D2 & $\mathrm{MS} 1 / 2$ & $1,90 \mathrm{c}$ \\
\hline A22 & MS $1 / 2$, carvão e polpa de banana & $2,30 \mathrm{c}$ \\
\hline $\mathrm{B} 22$ & MS $1 / 2$, carvão e água de coco & $4,40 \mathrm{~b}$ \\
\hline $\mathrm{C} 22$ & MS'1/2, carvão, p. banana e água coco & $1,40 \mathrm{c}$ \\
\hline $\mathrm{D} 22$ & MS $1 / 2$ e carvão & $5,10 \mathrm{~b}$ \\
\hline
\end{tabular}

*Médias seguidas pela mesma letra dentro da coluna não diferem estatisticamente entre si pelo teste de Scott-Knott a 5\% de probabilidade. Fonte: Dados da pesquisa.

Os resultados mostraram que a água de coco e o carvão ativado resultaram em um melhor desenvolvimento das orquídeas em decorrência do fato de ser um complexo nutritivo, no qual se encontra o hormônio citocinina, que estimula o crescimento (UTAMI; HARIYANTO; MANUHARA, 2017). Giatti e Lima (2007), trabalhando com gemas apicais e axilares do híbrido de Cattleya Blc Owen Holmes Ponkan x Brassavola digbiana $\mathrm{n}^{\mathrm{o}} 2$, obtiveram resultados semelhantes com número de brotos, com a utilização da água de coco no meio nutritivo. Porém, o trabalho de Ventura et al. (2002) foi divergente dos resultados obtidos neste trabalho, visto que seus explantes sofreram oxidação quando cultivados em meio de cultivo suplementado com água de coco.

$\mathrm{O}$ estado fisiológico da água de coco influencia diretamente no $\mathrm{pH}$ e na atividade de enzimas oxidativas. Sua composição química possui ácido málico e ácido cítrico que podem influenciar na oxidação das plantas (FERREIRA et al., 2016). No entanto, no presente trabalho, não foi observada oxidação em meio de cultivo suplementado apenas com água de coco, que pode ser em função da quantidade de sais deste composto, que estaria corroborando para o desenvolvimento das plântulas (Quadro 4).

Quadro 4 - Porcentagem de oxidação dos explantes de acordo com cada tratamento utilizando água de coco, polpa de banana e carvão ativado

\begin{tabular}{|c|l|c|}
\hline Abreviação & \multicolumn{1}{|c|}{ Tratamento } & $\%$ \\
\hline A & MS e polpa de banana & 30 \\
\hline B & MS e água de coco & 0 \\
\hline C & MS, polpa de banana e água de coco & 60 \\
\hline D & MS & 10 \\
\hline A11 & MS, carvão e polpa de banana & 30 \\
\hline B11 & MS, carvão e água de coco & 0 \\
\hline C11 & MS, carvão, p. banana e água de coco & 40 \\
\hline
\end{tabular}

\begin{tabular}{|c|l|c|}
\hline D11 & MS e carvão & 0 \\
\hline A2 & MS $1 / 2$ e polpa de banana & 50 \\
\hline B2 & MS $1 / 2$ e água de coco & 0 \\
\hline C2 & MS $1 / 2$, polpa banana e água de coco & 70 \\
\hline D2 & MS $1 / 2$ & 10 \\
\hline A22 & MS $1 / 2$, carvão e polpa de banana & 40 \\
\hline B22 & MS $1 / 2$, carvão e água de coco & 0 \\
\hline C22 & MS $1 \frac{2}{2}$ carvão, p. banana e água coco & 50 \\
\hline D22 & MS 12 e carvão & 0 \\
\hline
\end{tabular}

Fonte: Dados da pesquisa.

A baixa porcentagem de oxidação de explantes foi observada no meio de cultivo MS normal sem suplementação e no meio MS com a metade dos sais sem suplementação. A adição de carvão ativado e de água de coco nestes meios de cultivo resultou em uma melhora considerável, pois nestes tratamentos não foi observada a oxidação.

A oxidação dos explantes foi observada com mais intensidade (30 a $60 \%$ de explantes oxidados) em todos os tratamentos em meio de cultivo suplementado com polpa de banana. Os resultados diferem dos obtidos de Arditti e Ernest (1993), em que a adição da polpa de banana aumentou o número de brotos e, com os resultados de Pasqual et al. (2009), que apresentaram um aumento da parte aérea e a emissão de brotos laterais em plântulas de Cattleya loddigesii em meio de cultivo suplementado com polpa de banana. No presente experimento pode ter ocorrido a oxidação de sais, de reguladores de crescimento, de vitaminas e de aminoácidos que poderiam ter influenciado no aumento da taxa de oxidação dos explantes. Os tratamentos que continham polpa de banana não obtiveram um resultado satisfatório, apresentando a menor média de número de brotos igual a 0,50.

Os melhores resultados de número de brotos e porcentagem de oxidação foram obtidos nos tratamentos com água de coco $150 \mathrm{ml} \mathrm{L}^{-1}, 1500 \mathrm{mg} \mathrm{L}^{-1}$ de carvão ativado e meio MS e meio MS com a metade dos sais adicionados com carvão ativado. Estes resultados corroboram com os de Araujo et al. (2006), nos quais se utilizou meio Knudson $\mathrm{C}$ com carvão ativado no cultivo de Laelia tenebrosa. O uso do carvão ativado no meio de cultivo colabora no desenvolvimento das plântulas.

A combinação de vários meios de cultura e várias outras combinações de misturas complexas e aditivos podem afetar, direta e indiretamente, o desenvolvimento das plantas in vitro (KUNAKHONNURUK; INTHIMA; KONGBANGKERD, 2018). Por isso, há necessidade de fazer pesquisas para verificar qual é a melhor combinação destes fatores para uma melhor propagação e multiplicação de tais plantas (RODRIGUES, et al. 2015).

A utilização do carvão ativado no meio de cultura pode proporcionar um melhor crescimento da planta in vitro. Cada espécie de planta se adapta a uma certa quantidade de carvão adicionado ao meio, como relatado por Simões et al. (1999), que verificaram que a concentração de $1 \mathrm{~g} \mathrm{l}^{-1}$ de carvão proporcionou um melhor desenvolvimento de brotos de Epidendrum sp. e Dendrobium $s p$ 
A Figura 1 mostra o desenvolvimento dos explantes de o meio de multiplicação, ao qual é o meio comparativo em Lycaste $s p$. em seus respectivos tratamentos, juntamente com relação aos outros.

Figura 1 - Brotações de Lycaste sp. produzidas in vitro, diferentes concentrações de polpa de banana, água de coco, carvão ativado e meio MS. MC: meio comparativo, meio de multiplicação de orquídeas

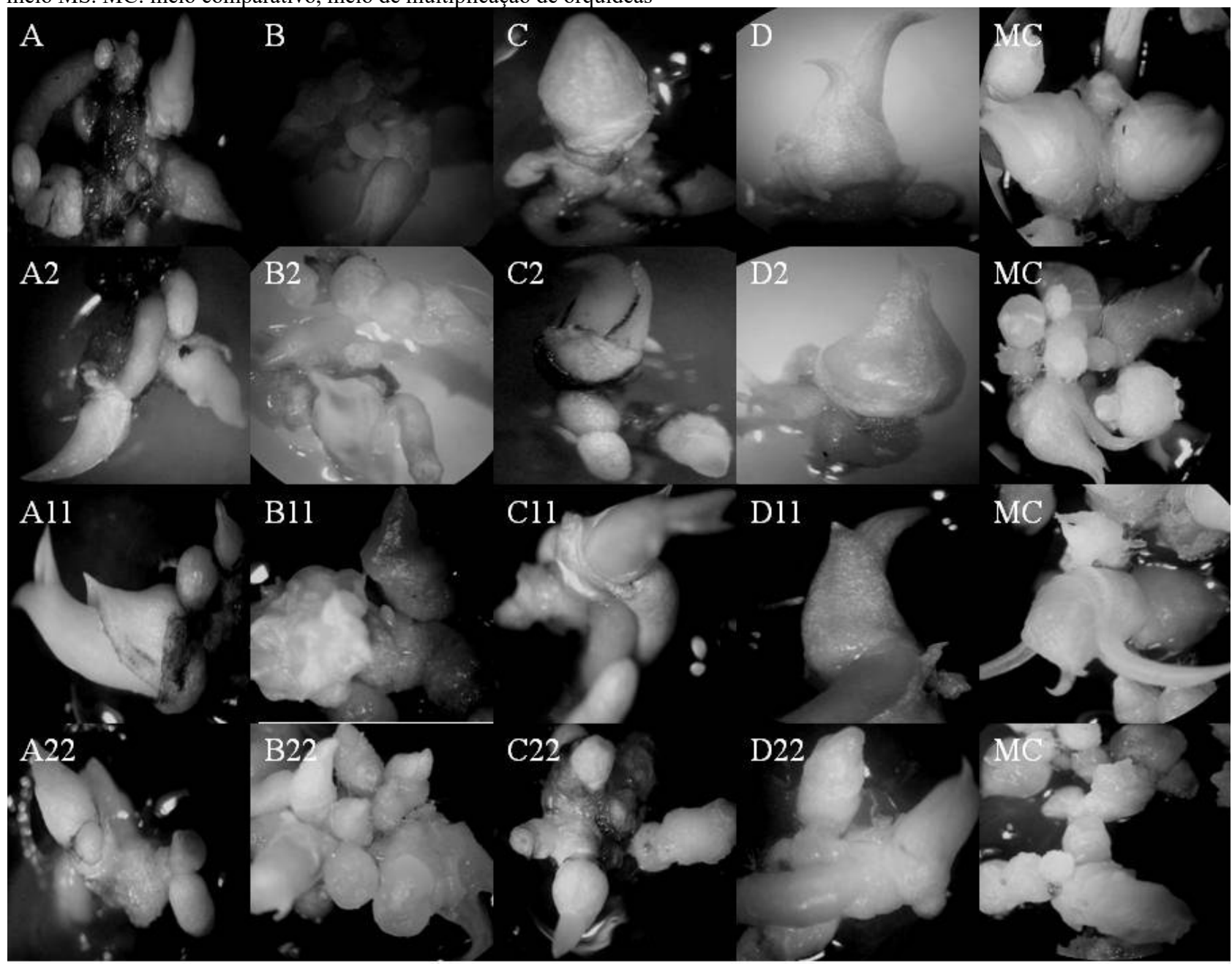

Fonte: Os autores.

O acréscimo de carvão ativado e água de coco ao meio nutritivo pode aumentar os custos de preparo, contudo esses podem ter um efeito no final do trabalho positivo, aumentando assim a taxa de multiplicação das plantas.

\section{Conclusão}

As diferentes composições dos meios nutritivos influenciam no crescimento e desenvolvimento dos explantes de orquídeas Lycaste spp. Os melhores resultados foram obtidos em cultivo em meio MS com a adição de água de coco e com carvão ativado.

\section{Referências}

ARAUJO, A.G. et al. Crescimento in vitro de Laelia tenebrosa (Orquidaceae) em diferentes concentrações de sais de Knudson C e carvão ativado. Plant Cell Cul Micropr. v.2, n.2, p.53-106, 2006.

ARDITTI, J.; ERNST, R. Micropropagation of orchids. New York: John Wiley, 1993.
ASGHAR, S. et al. In vitro propagation of orchid (Dendrobium nobile) var. Emma white. Afr. J. Biotec., v.10, n.16, p.3097-3103, 2011. doi: 10.5897/AJB10.401

BARRUETO CID, L.P. Citocininas em plantas superiores. In: BARRUETO CID, L.P. (Ed.) Hormônios vegetais em plantas superiores. Brasília: Embrapa Recursos Genéticos e Biotecnologia, 2005. p.58-79.

CALDAS, L.S. et al. Meios nutritivos. In: TORRES, A.C. et al. (Ed.). Cultura de tecidos e transformação genética de plantas. Brasília: EMBRAPA/CNPH, 1998. p.87-132.

CHYUAM-YIH, N.G.; SALEH, N.M.; ZAMAN, F.Q. In vitro multiplication of the rare and endangered slipper orchid, Paphiopedilum rothschildianum (Orchidaceae). African $J$. Biotec., v.9, n.14, p.2062-2068, 2010.

FERREIRA, L.T. et al. Germinação in vitro de gongora (Orchidaceae) em meios nutritivos simplificados. Plant. Cell. Cul. Micropr., v.12, n.1, p.20-26, 2016.

GIATTI, L.; LIMA, G.P.P. Ação do BAP na regeneração in vitro Blc Owen Holmes Ponkan x Brassavola digbiana $\mathrm{n}^{\circ}$ 2. Cienc. Agrotec,, v.31, n.5, p.1279-1285, 2007. doi:10.1590/S141370542007000500001 
KUNAKHONNURUK, B.; INTHIMA, P.; KONGBANGKERD, A. In vitro propagation of Epipactis flava Seidenf. an endangered rheophytic orchid: a first study on factors affecting asymbiotic seed germination, seedling development and greenhouse acclimatization. Plant. Cell. Tiss. Org. Cul., v.135, n.3, p.419432, 2018. doi: 10.1007 / s11240-018-1475-9

KURITA, F.M.K.; TAMAKI, V. In vitro growth of the bromeliad Alcantarea imperialis (Carrière) Harms with different concentrations of nitrogen. Acta Sci., Bio Sci., v.36, n.3 p.279285, 2014. doi: 10.4025/actascibiolsci.v36i3.22933

LONGO, A.E.O. et al. Micropropagação e bulbificação in vitro de alho (Allium sativum L.). Plant. Cell. Cul. Micropr., v.8, n.1/2, p.18-26, 2016.

MAMUN, A.A. et al. In vitro mass propagation from shoot tip of dendrobium red bull-an endangered epiphytic orchid. Plant. Tiss. Cul. Biotec., v.28, n.2, p.161-169, 2018. doi: 10.3329/ptcb. v28i2.39675

MENEGHETTI, E.C.; OLIVEIRA, L.S.; ALMEIDA, M. Multiplicação in vitro de Neoregelia johannis (Carriére) LB Smith em meio líquido sob diferentes concentrações de nutrientes. Iheringia, v.74, 2019. doi: 10.21826/2446$82312019 \mathrm{v} 74 \mathrm{e} 2019012$

MURASHIGE, T.; SKOOG, F. A revised medium for rapid growth and bioassays with tobacco tissue cultures. Physio Plant, n.15, p.473-497, 1962.

PASQUAL, M. et al. Fontes de nitrogênio, polpa de banana e ágar no desenvolvimento in vitro de plântulas de orquídea. Hort. Bras., n.27, p.211-216, 2009. doi: 10.1590/S0102-05362009000200016

RODRIGUES, L.A. et al. In vitro propagation of Cyrtopodium saintlegerianum rchb. f.(orchidaceae), a native orchid of the Brazilian savannah. Crop Breed Ap Biotec, v.15, n.1, p.10-17, 2015. doi: 10.1590/1984-70332015v15n1a2.
SANTOS-SEREJO, J. A. et al. Meios nutritivos para micropropagação de plantas. In: SOUZA, A.S.; JUNGHANS, T.G. (Ed.) Introdução a micropropagação de plantas. Cruz das Almas: Embrapa Mandioca e Fruticultura Tropical, 2006. p.7998.

SIMÕES, F.C.; PAIVA, P.D.O.; RODRIGUES, T.M. Efeito de diferentes meios de cultura, água de coco e carvão ativado na propagação in vitro de meristemas de Epidendrum $s p$. e Dendrobium $s p$. In: CONGRESSO BRASILEIRO DE FLORICULTURA E PLANTAS ORNAMENTAIS, 12., 1999, Jaboticabal. Anais... Jaboticabal, 1999. p.199.

SOUZA, C. et al. Cultivo in vitro de Epidendrum nocturnum (Orchidaceae) ocorrente no Cerrado da região Centro-Oeste. Rodriguésia, v.67, n.4, 2016. doi:10.1590/2175-7860201667418

TEIXEIRA, A.F.S et al. Efeito da associação micorrízica e de fatores abióticos sobre o desenvolvimento e a distribuição de Oeceoclades maculata (Lindl.) Lindl. em sub-bosque de abacateiros. Evol Conserv. Biod., v.6, n.2, p.23-32, 2016. doi: 10.7902/ecb.v6i2.70

TISSERAT, B. Factors involved in the production of plantlets from date palm callus culture. Euphytica, v.13, p.201-214, 1982.

UTAMI, E.S.W.; HARIYANTO, S.; MANUHARA, Y.S.W. In vitro propagation of the endangered medicinal orchid, Dendrobium lasianthera JJ Sm through mature seed culture. Asian Pac. J. Trop. Biomed., v.7, n.5, p.406-410, 2017. doi: 10.1016/j.apjtb.2017.01.011

VENTURA, G.M. et al. Organogênese in vitro a partir de gemas apicais e axilares de plantas adultas de orquídeas do grupo Cattleya. Rev. Ceres, v.47, n.286, p.613-628, 2002.

ZENG, S. et al. In vitro propagation of Paphiopedilum orchids. Crit. Rev. Biotec., v.36, n.3, p.521-534, 2016. doi: 10.3109/07388551.2014.993585. 